ARTICLE

\title{
Efficient $\mathrm{CO}_{2}$ electroreduction on facet-selective copper films with high conversion rate
}

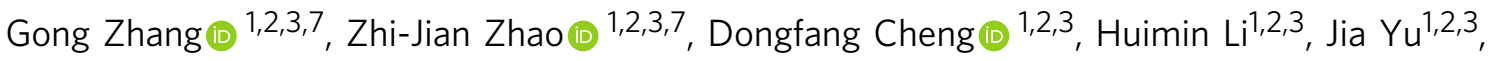 \\ Qingzhen Wang ${ }^{1,2,3}$, Hui Gao $1,2,3$, Jinyu Guo ${ }^{4}$, Huaiyuan Wang ${ }^{1,2,3}$, Geoffrey A. Ozin (1) ${ }^{5}$, Tuo Wang (1) ${ }^{1,2,3 凶} \&$ \\ Jinlong Gong (1) 1,2,3,6凶
}

Tuning the facet exposure of $\mathrm{Cu}$ could promote the multi-carbon $(\mathrm{C} 2+)$ products formation in electrocatalytic $\mathrm{CO}_{2}$ reduction. Here we report the design and realization of a dynamic deposition-etch-bombardment method for $\mathrm{Cu}(100)$ facets control without using capping agents and polymer binders. The synthesized $\mathrm{Cu}(100)$-rich films lead to a high Faradaic efficiency of $86.5 \%$ and a full-cell electricity conversion efficiency of $36.5 \%$ towards $\mathrm{C} 2+$ products in a flow cell. By further scaling up the electrode into a $25 \mathrm{~cm}^{2}$ membrane electrode assembly system, the overall current can ramp up to $12 \mathrm{~A}$ while achieving a singlepass yield of $13.2 \%$ for $\mathrm{C} 2+$ products. An insight into the influence of $\mathrm{Cu}$ facets exposure on intermediates is provided by in situ spectroscopic methods supported by theoretical calculations. The collected information will enable the precise design of $\mathrm{CO}_{2}$ reduction reactions to obtain desired products, a step towards future industrial $\mathrm{CO}_{2}$ refineries.

\footnotetext{
${ }^{1}$ School of Chemical Engineering and Technology, Tianjin University, Tianjin, China. ${ }^{2}$ Key Laboratory for Green Chemical Technology of Ministry of Education, Tianjin University, Tianjin, China. ${ }^{3}$ Collaborative Innovation Center of Chemical Science and Engineering (Tianjin), Tianjin, China. ${ }^{4}$ Department of Chemical Engineering, Stanford University, Stanford, CA, USA. ${ }^{5}$ Department of Chemistry, University of Toronto, 80 St. George Street, Toronto, ON, Canada. ${ }^{6}$ Joint School of National University of Singapore and Tianjin University, International Campus of Tianjin University, Binhai New City, Fuzhou, China. ${ }^{7}$ These authors contributed equally: Gong Zhang, Zhi-Jian Zhao. ®email: wangtuo@tju.edu.cn; jlgong@tju.edu.cn
} 
T he renewable electricity-powered $\mathrm{CO}_{2}$ reduction has been considered as one promising route to the product of chemical feedstocks, which might close the carbon loop ${ }^{1,2}$. Multi-carbon $(\mathrm{C} 2+)$ products such as ethylene, ethanol, n-propanol, etc. are important raw materials in the chemical industry or can be used directly as fuels, thus the efficient $\mathrm{CO}_{2}$ reduction to $\mathrm{C} 2+$ products system is essential to the production of high-value commodity chemicals with a net negative carbon emissions footprint. Among various $\mathrm{CO}_{2}$ reduction catalyst materials, $\mathrm{Cu}$ has been studied extensively as it can produce $\mathrm{C} 2+$ products with appreciable selectivity ${ }^{3}$. Among numerous ways to promote $\mathrm{C} 2+$ formation ${ }^{4-8}$, adjusting the facet of Cu-based catalysts is an effective method since the dimerization reaction is facet sensitive ${ }^{9}$. According to the theoretical calculations, the $\mathrm{Cu}(100)$ facet can significantly lower the dimerization energy barrier ${ }^{10}$. Thus, it is an effective approach to improve the selectivity toward $\mathrm{C} 2+$ by designing $\mathrm{Cu}$ catalysts with $\mathrm{Cu}(100)$ as the dominant exposed facet ${ }^{10}$. Colloidal chemistry is an inexpensive, simple, and widely used method for facet exposure control. It produces catalysts with preferential exposure of specific facets by using capping agents to manipulate surface energies, which changes the growth rates of different facets to alter the shape of nanocatalysts ${ }^{11,12}$. Recently, colloidally synthesized $\mathrm{Cu}$ nanocubes rich in $\mathrm{Cu}(100)$ facets were shown to achieve a Faradaic efficiency (F.E.) of $\sim 57 \%$ towards ethylene ${ }^{13}$. However, the corresponding electricity conversion efficiency (E.C.E.) and single-pass yield have been rarely reported. Some studies also propose that the intermediates along the $\mathrm{CO}_{2}$ reduction pathways can control the formation of specific facets, where the adsorption of the intermediates plays a role analogous to that of capping agents ${ }^{14,15}$. Nonetheless, these approaches require specific chemicals, such as capping agents, to be selectively adsorbed on particular facets to reduce the surface energy ${ }^{11,12}$. However, the effectiveness of the colloidal method might compromise to some extent since low-index facets of fcc transition metals often possess similar surface energies $\left(1.25 \mathrm{~J} \mathrm{~cm}^{-2}\right.$ for $\mathrm{Cu}(111)$ and $1.43 \mathrm{~J} \mathrm{~cm}^{-2}$ for $\mathrm{Cu}(100))^{15,16}$. Besides, residual capping agents left on the catalyst surface could block catalytically active sites ${ }^{17,18}$. Moreover, the colloidally synthesized catalyst needs to be dispersed in a solution containing polymer binders (such as Nafion) to form a wellmixed ink before being drop-casted on the conductive support to form an electrode, which is not always compatible with the catalytic electrode system due to agglomeration and the peeling-off of catalysts especially when scaling up the electrodes ${ }^{19,20}$. At the same time, due to the existence of the cross-linked network formed by polymer binders ${ }^{21}$, the contact between the colloidally synthesized catalyst and the conductive substrate is weak ${ }^{22,23}$, and plenty of active sites are further encapsulated ${ }^{20}$, which will lead to slow electron transfer and low E.C.E. Thus, it is highly desirable to develop a novel approach to replace colloidal synthesis to prepare $\mathrm{Cu}$ electrodes with dominant (100) facets in one-step without using capping agents and polymer binders to achieve a high E.C.E. and a single-pass yield.

In this work, we describe the design and realization of a dynamic deposition-etch-bombardment process to produce $\mathrm{Cu}(100)$-rich films as the $\mathrm{CO}_{2}$ reduction electrode in one-step, which could break the limitation of using capping agents while avoiding the issue of catalyst loading faced by conventional methods. This $\mathrm{Cu}(100)$-rich film yields a full-cell electricity conversion efficiency of $40.5 \%$ towards $\mathrm{C} 2+$ products in the $4 \mathrm{~cm}^{2}$ membrane electrode assemble (MEA) system. This facile one-step method also makes it easier for scaling up electrodes, with a $25 \mathrm{~cm}^{2}$ electrode exhibiting a $13.2 \%$ single-pass yield of $\mathrm{C} 2+$ product at a total current of $12 \mathrm{~A}$ in the MEA system. Thanks to the controllable structure, the influence of facets on the adsorption and activation of intermediates is further revealed by in situ spectroscopy and density functional theory (DFT) calculation.

\section{Results}

To amplify, when $\mathrm{Cu}$ atoms with high kinetic energy bombard the deposited $\mathrm{Cu}$ film, the high local temperature causes dynamic recrystallization 24,25 . Facets with the relatively loose atomic arrangement, like $\mathrm{Cu}(100)$ (Supplementary Fig. 1c), would receive less damage and remain at lower temperatures thereby acting as recrystallization centers ${ }^{26,27}$. As a result, the $\mathrm{Cu}(100)$ will preferentially grow, replacing the more densely packed $\mathrm{Cu}(111)$ facet (Supplementary Fig. 1b). Therefore, by controlling the kinetic energy of bombarding copper atoms, the exposure ratio of $\mathrm{Cu}(100)$ facets could be adjusted.

To realize the simultaneous deposition, etching, and bombardment, high-energy radio frequency (RF) sputtering was adopted to prepare $\mathrm{Cu}(100)$-rich films (details in the "Methods"), which enables the direct deposition of catalysts on carbon-based gas diffusion layers (GDLs) as electrodes in one-step (Supplementary Fig. 1a). Three typical types of sputtered $\mathrm{Cu}$ films with different $\mathrm{Cu}(100)$ proportions were obtained by adjusting the RF power to control the kinetic energy $\left(\mathrm{E}_{\mathrm{k}}\right)$ of the bombarding $\mathrm{Cu}$ atoms (Fig. 1a, details in "Methods"), resulting in low-power, mediumpower, and high-power sputtered $\mathrm{Cu}$ films (denoted as LS-Cu, MS$\mathrm{Cu}, \mathrm{HS}-\mathrm{Cu}$, respectively). The obtained $\mathrm{HS}-\mathrm{Cu}$ film is prone to expose the $\mathrm{Cu}(100)$ facet, as evidenced by transmission electron microscopy (TEM, Supplementary Fig. 2a) and X-ray diffraction (XRD, Supplementary Fig. 3a), while LS-Cu tends to form $\mathrm{Cu}(111)$ facet (Supplementary Figs. 2c and 3a). The energy of $\mathrm{Cu}$ atoms generated by thermal evaporation ${ }^{2}$ or low-rate sputtering process $^{4,28}$ is usually not high enough, rendering $\mathrm{Cu}$ films that favor the $\mathrm{Cu}(111)$ facet exposure similar to LS-Cu. As different $\mathrm{Cu}$ facets feature distinctive $\mathrm{OH}^{-}$electrochemical adsorption behaviors ${ }^{29,30}$, surface structures of these samples were probed by using the $\mathrm{OH}^{-}$ electroadsorption technique (the features were labeled by comparing the CVs to those of single crystals shown in Supplementary Fig. 4$)^{31}$. The cyclic voltammograms $(\mathrm{CVs})$ of $\mathrm{OH}_{\mathrm{ads}}$ peaks (Supplementary Fig. 3b) reveal that the presence of $\mathrm{Cu}(111)$ is suppressed in the HS-Cu film. Therefore, this deposition-etchbombardment process successfully realizes the replacement of $\mathrm{Cu}(100)$ to $\mathrm{Cu}(111)$ facets, adjusting the facet exposure of $\mathrm{Cu}$.

However, these obtained $\mathrm{Cu}$ films (i.e. LS-Cu, MS-Cu, HS-Cu) lack a large electrochemically active surface area (ECSA, Supplementary Fig. 26 and Supplementary Table 1) to realize high-rate $\mathrm{CO}_{2}$ electrolysis ${ }^{32}$. To increase the ECSA, an oxidation-reduction procedure was included, during which the preferential exposure of $\mathrm{Cu}(100)$ could be maintained. Specifically, molecular $\mathrm{O}_{2}$ (with a constant partial pressure of $0.67 \mathrm{~Pa}$ ) was introduced during this deposition-etch-bombardment process to obtain $\mathrm{Cu}_{2} \mathrm{O}$ as precatalysts, which could be further reduced during the pre-reduction process $(-0.5 \mathrm{~V}$ vs. the $\mathrm{RHE})$ under the same $\mathrm{CO}_{2}$ reduction conditions to metallic $\mathrm{Cu}$ with the $\mathrm{Cu}(100)$ facets retained (Fig. 1a, details in "Methods"). The same crystallographic relationship exists between the oxidation and reduction processes for $\mathrm{Cu}(100) /(111)$ and $\mathrm{Cu}_{2} \mathrm{O}(100) /(111)^{10,33}$, since oxygen atoms could pack into the interlayer sites of different planes of $\mathrm{Cu}$, causing a lattice expansion while retaining the underlying fcc crystal structure with the inclusion of oxygen $^{33}$. Therefore, the introduction of an oxidation-reduction step will be able to increase the ECSA while retaining the same $\mathrm{Cu}(100)$ exposure. Correspondingly, samples obtained by reactive sputtering followed by reduction are referred to as low-power, medium-power, and high-power reactively sputtered $\mathrm{Cu}$ films followed by reduction (denoted as LRS-Cu, MRS-Cu, and HRS-Cu). Typical XRD patterns (Supplementary Fig. 5a) show 


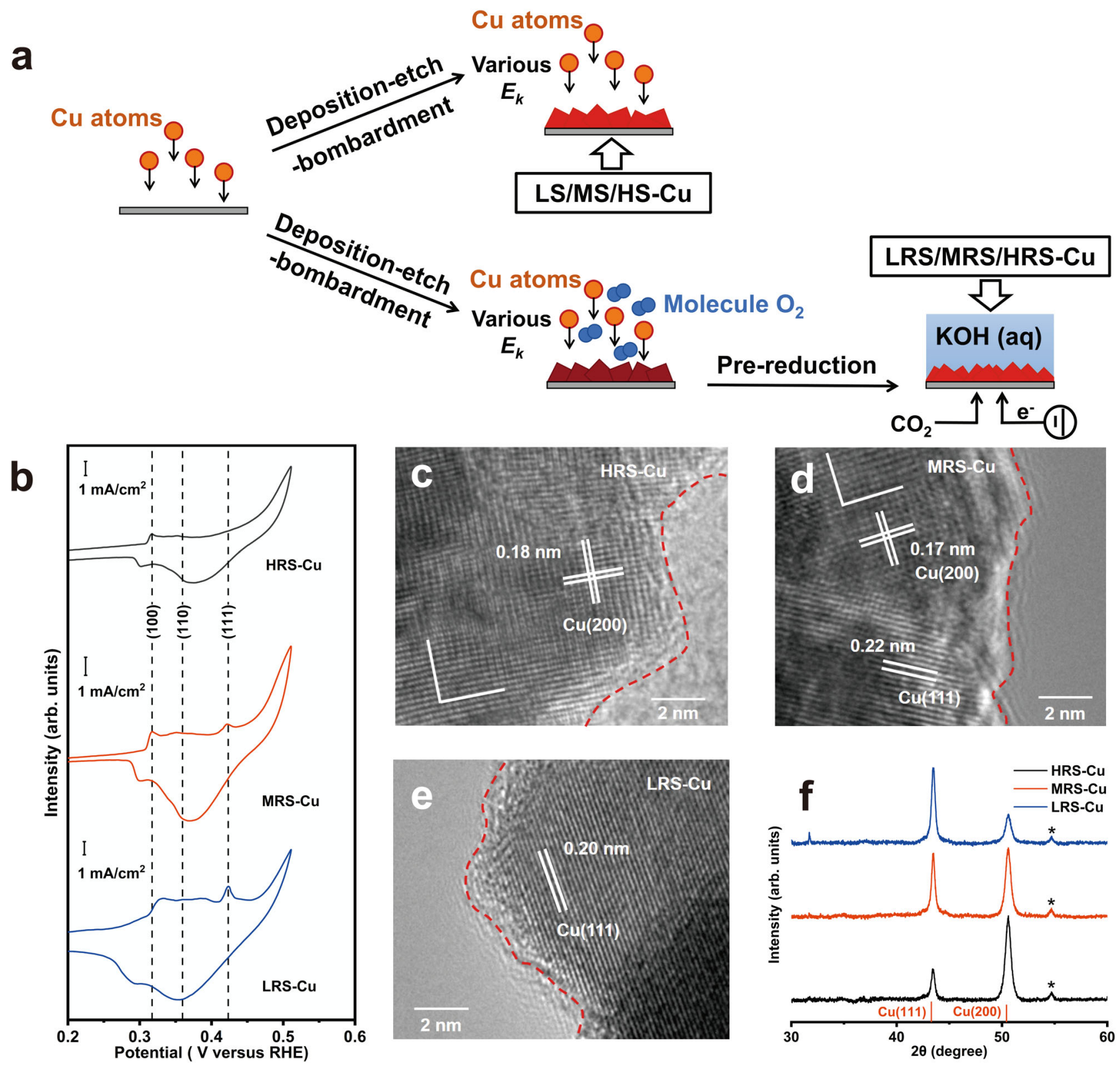

Fig. 1 characterization of various $\mathbf{C u}$ films. a A schematic illustration of the synthesis process for LS/MS/HS-Cu and LRS/MRS/HRS-Cu. b Voltammograms of resulting electrodes collected immediately after pre-reduction. Typical TEM images of $\mathbf{c} H R S-C u$, $\mathbf{d} M R S-C u$, and $\mathbf{e} L R S-C u$. $\mathbf{f} T y p i c a l$ XRD patterns of resulting electrodes. As visual aids, the red dash line indicates the surfaces of the resulting electrodes. The precatalysts of HRS/MRS/LRS-Cu were pre-reduced under $-0.5 \mathrm{~V}$ versus the RHE for $1 \mathrm{~h}$, and the other conditions of prereduction are the same as that of the $\mathrm{CO}_{2}$ reduction. The labeling of $\mathrm{Cu}(200)$ is used for easier comparison with XRD, in which only (200), the second-order diffraction of (100) could be detected. The peaks marked with an asterisk in XRD patterns originate from carbon-based GDL substrate.

that all the obtained precatalysts are mainly $\mathrm{Cu}_{2} \mathrm{O}$, which is confirmed by X-ray photoelectron spectroscopy (XPS), Auger spectroscopy (Supplementary Fig. 5b, c), and Raman spectroscopy (Supplementary Fig. 4d). The same type of $\mathrm{Cu}$ facets distribution could be maintained for these electrodes regardless of the oxidationreduction process according to TEM (Fig. 1c-e, more images of different samples are also provided in Supplementary Figs. 7-9) and XRD (Fig. 1f), consistent with previous reports ${ }^{10,34}$. The different proportions of $\mathrm{Cu}(100)$ facet on these samples (i.e. HRS-Cu, MRS$\mathrm{Cu}$, and LRS- $\mathrm{Cu}$ ) are also evidenced by the electrochemical $\mathrm{OH}^{-}$ adsorption peaks on $\mathrm{Cu}(100)$ and $\mathrm{Cu}(111)$ at potentials of $\sim 0.33$ and $0.43 \mathrm{~V}$ versus the RHE (Fig. 1b). Meanwhile, large ECSA is obtained for these samples (Supplementary Table 1). Thus, this one-step surfactant-free route indeed leads to nanostructured $\mathrm{Cu}$ films with preferred $\mathrm{Cu}(100)$ exposure and high surface area that could be further used as $\mathrm{CO}_{2}$ reduction electrodes.

To further explore the importance of the high-energy atom bombardment proposed above, another control electrode was prepared. $\mathrm{Cu}_{2} \mathrm{O}$ precatalyst (Supplementary Fig. 10) was obtained through wet chemistry without using capping agents (denoted as $\mathrm{W}-\mathrm{Cu}$ ). Then this control $\mathrm{Cu}_{2} \mathrm{O}$ precatalyst was airbrushed onto GDEs and pre-reduced to $\mathrm{Cu}$ under $\mathrm{CO}_{2}$ reduction conditions to form a control electrode (details in "Methods"). The typical TEM image shows that the lattice fringes corresponding to $\mathrm{Cu}(111)$ are widely distributed in this control electrode (Supplementary Fig. 11a $)^{32}$. These observations are in good agreement with the XRD pattern (Supplementary Fig. 11b) and $\mathrm{CV}$ of $\mathrm{OH}_{\text {ads }}$ peaks (Supplementary Fig. 11c). It is also worth noting that LRS-Cu, 
MRS-Cu, HRS- $\mathrm{Cu}$, and W-Cu all consist of metallic $\mathrm{Cu}$ only without residual oxides after the pre-reduction, as confirmed by in-situ Raman spectroscopy (Supplementary Fig. 12, details in "Methods"). Thus, this control experiment reveals that the lack of high-energy atom bombardment during the synthesis process would result in the dominant exposure of $\mathrm{Cu}(111)$ facets, similar to the scenario of lacking capping agents that are widely used in the synthesis of $\mathrm{Cu}$ nanocubes 34,35 .

Before performance testing, it was confirmed that different samples (LRS-Cu, MRS-Cu, HRS-Cu, and $\mathrm{W}-\mathrm{Cu}$ ) possess similar mass loadings (Supplementary Table 2), catalyst layer thickness (Supplementary Fig. 13) and morphology (Supplementary Fig. 14) of $\mathrm{Cu}$, which ensures a fair comparison to explore the activity difference among various samples ${ }^{36-39}$. The activities were evaluated at different potentials using $2 \mathrm{M} \mathrm{KOH}$ (aq.) as the electrolyte (Fig. 2a and Supplementary Figs. 16-19, details in "Methods") in a flow cell electrolyzer (Supplementary Fig. 15) for $\mathrm{CO}_{2}$ reduction with an effective electrode geometric area of $\sim 0.64$ $\mathrm{cm}^{2}$ for both cathode and anode. As for HRS-Cu, the products detected in significant quantities were ethylene, ethanol, n-propanol, and CO. At more negative potentials, a small amount of methane was produced, and the remaining charge was attributed to the competing hydrogen evolution reaction (Fig. 2b). Compared with the control samples, the HRS-Cu exhibits a maximum F.E. of $58.6 \%$ for ethylene, $86.6 \%$ for $\mathrm{C} 2+$ products (containing ethylene). Consistently, the HRS-Cu sample also exhibits the largest ethylene and $\mathrm{C} 2+$ products partial current densities (Fig. 2c, d and Supplementary Fig. 17c, d) among the four samples at all applied potentials. Moreover, at the applied potential of $-0.85 \mathrm{~V}$ versus the $\mathrm{RHE}$, the $\mathrm{C} 2+$-to- $\mathrm{C} 1$ ratio of the HRS-Cu electrode reaches about 15.2, which largely outperforms that of its counterparts (Supplementary Fig. 18). Due to the close contact between the catalytic $\mathrm{Cu}$ film and the GDL substrate, the reaction system could exhibit higher E.C.E. The corresponding full-cell E.C.E. towards ethylene and $\mathrm{C} 2+$ products of this HRS-Cu-based reaction system reaches 24.8 and $36.5 \%$, respectively, exceeding the efficiency of many other reaction systems reported so far (see below). The stability of the HRS-Cu was also examined under a constant applied potential of $-0.75 \mathrm{~V}$ versus the RHE for $4.5 \mathrm{~h}$ (270 min), where ethylene and C2+ F.E.s remained stable over the test duration (Fig. 2e and Supplementary Fig. 19). Although the surface of the $\mathrm{Cu}$-based catalysts may undergo reconstruction during the reaction to obtain $\mathrm{Cu}(100)^{40}$, the HRS-Cu, MRS-Cu, and LRS-Cu samples after use show similar surface exposures as before the reaction (Supplementary Figs. 20-22), indicating that the reconstruction process could not significantly change the main facet exposure, and thus surface reconstruction alone cannot guarantee electrodes similar to the HRS-Cu (showing a predominant $\mathrm{Cu}(100)$ exposure without undergoing reconstruction). The mass of the HRS-Cu sample after the reaction is also almost the same as that before the reaction (Supplementary Table 3), which further indicates that the firm conjunction between the substrate and the active composition. If the hydrophobicity of GDLs can be further improved ${ }^{2}$ and the reaction rate of carbonate formation can be reduced ${ }^{41}$, the stability of the sample in the flow cell will be longer.

To examine the influence of $\mathrm{Cu}(100)$ exposure over $\mathrm{C} 2+$ products formation in $\mathrm{CO}_{2}$ reduction, Tafel analyses (Supplementary Fig. 23) were conducted on various samples. It is clear that $\mathrm{C} 2+$ products formation depends strongly on the surface structure. With the increasing exposure of $\mathrm{Cu}(100)$ facets, a lower change of the Tafel slope can be observed, which indicates that the $\mathrm{Cu}(100)$ surface is beneficial to the formation of $\mathrm{C} 2+$ products. However, the Tafel slope of all samples locates at approximately $120-140 \mathrm{mV} \mathrm{dec}^{-1}$, implying that they might share the same rate-determining step (details in "Methods"), which is further validated by the results of $\mathrm{CO}$ partial pressure dependence experiments (Supplementary Figs. 24, 25). To further compare the reaction rates, the performances are normalized to the ECSA (details in "Methods"). Obviously, the current densities of specific ethylene and $\mathrm{C} 2+$ products of HRS-Cu are larger than other electrodes (Supplementary Fig. 27), which indicates the highest intrinsic activities of HRS-Cu.

Understanding the behaviors of adsorbates is essential to the inquiry into the nature of the catalytic activity. Thus, in-situ attenuated total reflectance (ATR)-surface-enhanced infrared absorption spectroscopy (ATR-SEIRAS, details in "Methods") was applied to investigate the effect of facets exposure on the adsorption of intermediates. When the potential is swept from -0.1 to $-1.5 \mathrm{~V}$ versus the RHE, a positive band centered at $\sim 2050 \mathrm{~cm}^{-1}$ which corresponds to the linear-bond $\mathrm{CO}\left(\mathrm{CO}_{\mathrm{L}}\right.$, a reactive adsorbed species) is observed on all electrodes (Fig. 3a-c and Supplementary Fig. 28) ${ }^{42-44}$. Meanwhile, a small positive band centered at $\sim 1800 \mathrm{~cm}^{-1}$, which corresponds to the bridge-bond $\mathrm{CO}\left(\mathrm{CO}_{\mathrm{B}} \text {, an unreactive adsorbed species }\right)^{44}$ is also observed on the surface of other samples except the HRS-Cu. These results of the ATR-SEIRAS are also corroborated by the corresponding Raman spectra, where the HRS-Cu surface was covered by abundant $\mathrm{CO}_{\mathrm{L}}{ }^{45,46}$, while the LRS-Cu surface exhibited a pronounced appearance of $\mathrm{CO}_{\mathrm{B}}$ (Supplementary Fig. 30). The appearance of $\mathrm{CO}_{\mathrm{B}}$ might result from the interconversion of $\mathrm{CO}_{\mathrm{L}}$. According to the literature, when the ${ }^{*} \mathrm{CO}$ (*denotes the adsorbed species) coverage of the electrode decreases, a fraction of $\mathrm{CO}_{\mathrm{L}}$ would convert to $\mathrm{CO}_{\mathrm{B}}{ }^{44}$. Therefore, the increase of $\mathrm{CO}_{\mathrm{B}}$ ratio reveals the reduction of surface ${ }^{*} \mathrm{CO}$ coverage. By calculating the $\mathrm{CO}_{\mathrm{B}}$ to $\mathrm{CO}_{\mathrm{L}}$ ratio of different samples, the ${ }^{*} \mathrm{CO}$ coverage might decrease as the exposure of $\mathrm{Cu}(100)$ facets decreases (Supplementary Fig. 29). Normally, ${ }^{*} \mathrm{H}$ and ${ }^{*} \mathrm{CO}$ occupy most of the surface sites, so they are in direct competition with each other for surface sites. Meanwhile, the surface coverage of ${ }^{*} \mathrm{CO}$ eventually influences the distribution of products derived from $\mathrm{CO}_{2}$ reduction. It has been previously speculated that when the surface cannot maintain a high ${ }^{*} \mathrm{CO}$ coverage, the corresponding ${ }^{*} \mathrm{H}$ coverage will increase, inhibiting the dimerization of $* \mathrm{CO}$ to produce $\mathrm{C} 2+$ products, thereby shifting the selectivity to $\mathrm{C} 1$ products and $\mathrm{H}_{2}{ }^{47-49}$, which is also demonstrated by the results of our $\mathrm{CO}$ partial pressure dependence experiments (Supplementary Figs. 24, 25). Meanwhile, the results of $\mathrm{CO}_{2}$ reduction performance support the above speculation. The LRS-Cu and the $\mathrm{W}-\mathrm{Cu}$ with a lower exposure of $\mathrm{Cu}(100)$ facets exhibit the highest F.E. of methane, meanwhile, the methane F.E. increases rapidly as the potential becomes negative (Supplementary Fig. 31). Thus, these ATR-SEIRAS results prove that $\mathrm{Cu}(100)$ facet might be a type of strong ${ }^{*} \mathrm{CO}$ adsorption site, and a higher exposure of $\mathrm{Cu}(100)$ facets is beneficial to the increase of strong adsorption sites on the surface that maintains a higher * $\mathrm{CO}$ coverage on the surface, thereby leading to the catalyst with a higher $\mathrm{C}-\mathrm{C}$ coupling performance, which is also supported by other experimental and computational studies ${ }^{50-52}$

Since the ATR-SEIRAS cannot directly provide the adsorption energy and activation barrier of the intermediate, DFT calculations on $\mathrm{Cu}(111)$ and $\mathrm{Cu}(100)(3 \times 3)$ models were performed to further understand the facet exposure effect (Supplementary Fig. 32, details in "Methods"). Based on the Tafel analysis and CO partial pressure dependence study (Supplementary Figs. 23, $24)$, the energetics of *OCCO formation is chosen as the main consideration. Previous work has found that the solvent and cation effects can stabilize $* \mathrm{COCO}$, hence an appropriate electrochemical interface was built up to explore the mechanism of this dimerization procedure (Fig. $3 \mathrm{~d}$ and Supplementary Figs. 34-36 $)^{53}$. 

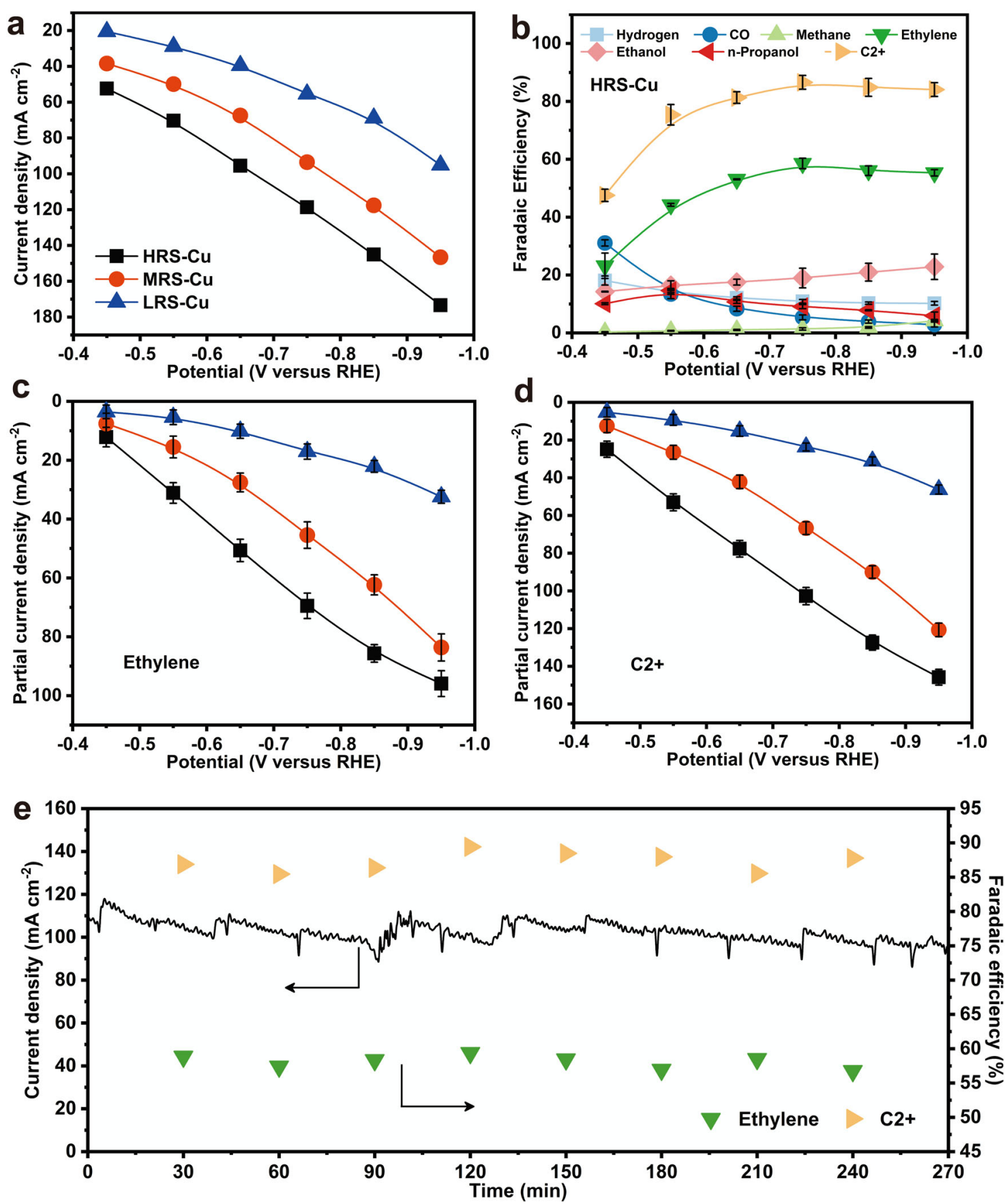

Fig. 2 Catalytic performance of various Cu films. a Current-voltage (I- $\mathrm{V})$ curves on various electrodes measured in $\mathrm{CO}_{2}-\mathrm{flowed} 2 \mathrm{M} \mathrm{KOH}$ electrolytes. b Faradaic efficiencies of $\mathrm{CO}_{2}$ reduction products on the HRS-Cu sample as a function of different applied potentials. $\mathbf{c}$ Ethylene and $\mathbf{d} \mathrm{C} 2+$ products partial current densities obtained on various samples at different applied potentials. e Stability test over a span of $4.5 \mathrm{~h}(270 \mathrm{~min})$ of $\mathrm{CO}_{2}-$ electrolysis in $2 \mathrm{M}$ $\mathrm{KOH}$ (aq.) at $-0.75 \mathrm{~V}$ versus the RHE. The oscillation of the current density is due to the repeated release of $\mathrm{O}_{2}$ bubbles in the anode side of the flow cell. $\mathrm{C} 2+$ products include ethylene, ethanol, and $\mathrm{n}$-propanol. Error bars represent the standard deviation from at least three independent measurements.

From the DFT calculation results, the binding of $* \mathrm{CO}$ is the weakest on the $\mathrm{Cu}(111)$ facet (Supplementary Fig. 33), which is not suitable to build up a sufficient coverage of $* \mathrm{CO}$ on the surface to promote the kinetics of $\mathrm{C}-\mathrm{C}$ coupling. Therefore, LRS$\mathrm{Cu}$ and $\mathrm{W}-\mathrm{Cu}$ would shorten the ${ }^{*} \mathrm{CO}$ stay and reduce the ${ }^{*} \mathrm{CO}$ coverage as compared to HRS-Cu, leading to a higher CO F.E. (Supplementary Fig. 16). In addition, the barriers of various $\mathrm{C}-\mathrm{C}$ coupling processes are always higher on the $\mathrm{Cu}(111)$ facet than on $\mathrm{Cu}(100)$ facet, implying that ${ }^{*} \mathrm{CO}$ dimerization is the most sluggish step on the $\mathrm{Cu}(111)$ facet (Fig. 3e). Thus, LRS-Cu and $\mathrm{W}-\mathrm{Cu}$ are less active in catalyzing the reduction of $\mathrm{CO}_{2}$ to $\mathrm{C} 2+$ products. These theoretical calculations are in good agreement with our ATR-SEIRAS and performance test results.

Due to the impressive E.C.E of this HRS-Cu-based reaction system, a PV-EC system (Fig. 4a) was further constructed to demonstrate the photosynthesis of $\mathrm{C} 2+$ products. Using the same test conditions (electrolyzer, cathode, anode, and electrolyte, details in "Methods") for measuring the $\mathrm{CO}_{2}$ reduction performance on the cathode side (as in Fig. 2), it is found that an overall cell voltage of about $2.5 \mathrm{~V}$ is required (Fig. $4 \mathrm{~b}$ ) to obtain an operating current density varying from 60 to $70 \mathrm{~mA} \mathrm{~cm}^{-2}$ (Fig. 2a), which could be translated to a cathodic potential of 

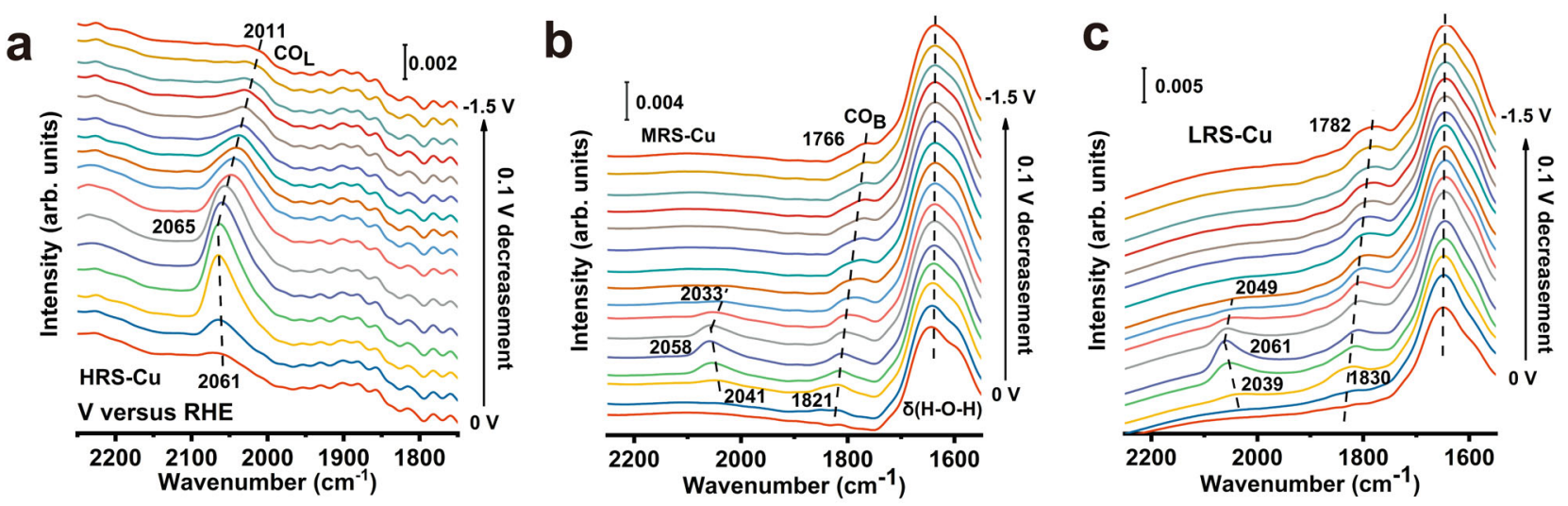

d

$\mathrm{Cu}(111)$
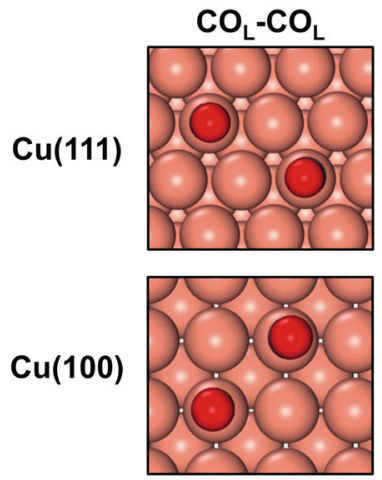

$\mathrm{CO}_{\mathrm{B}}-\mathrm{CO}_{\mathrm{L}}$
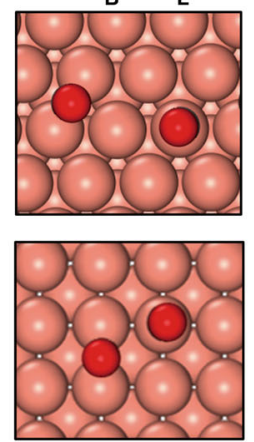

$\mathrm{CO}_{\mathrm{B}}-\mathrm{CO}_{\mathrm{B}}$
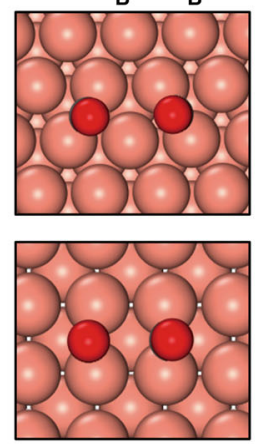

e

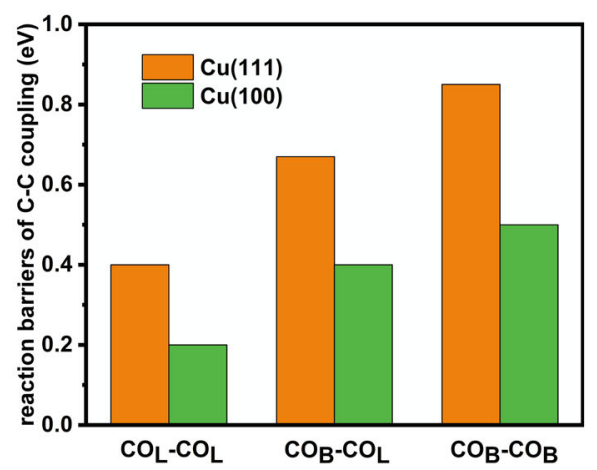

Fig. 3 Spectroscopic investigations of various $\mathbf{C u}$ films and DFT calculations on different $\mathbf{C u}$ facets. In situ ATR-SEIRAS spectra of a HRS-Cu; $\mathbf{b}$ MRS-Cu; c LRS-Cu; $\mathbf{d}$ adsorption geometry for different $\mathrm{C}-\mathrm{C}$ coupling precursors (i.e., $\mathrm{CO}_{L}-\mathrm{CO}_{L}, \mathrm{CO}_{B}-\mathrm{CO}_{L}, \mathrm{CO}_{B}-\mathrm{CO}_{B}$ ), where solvent molecules are not presented to show the adsorbate configurations; e reaction barriers for $\mathrm{C}-\mathrm{C}$ coupling from different precursors on $\mathrm{Cu}(100)$ and $\mathrm{Cu}(111)$ facets.
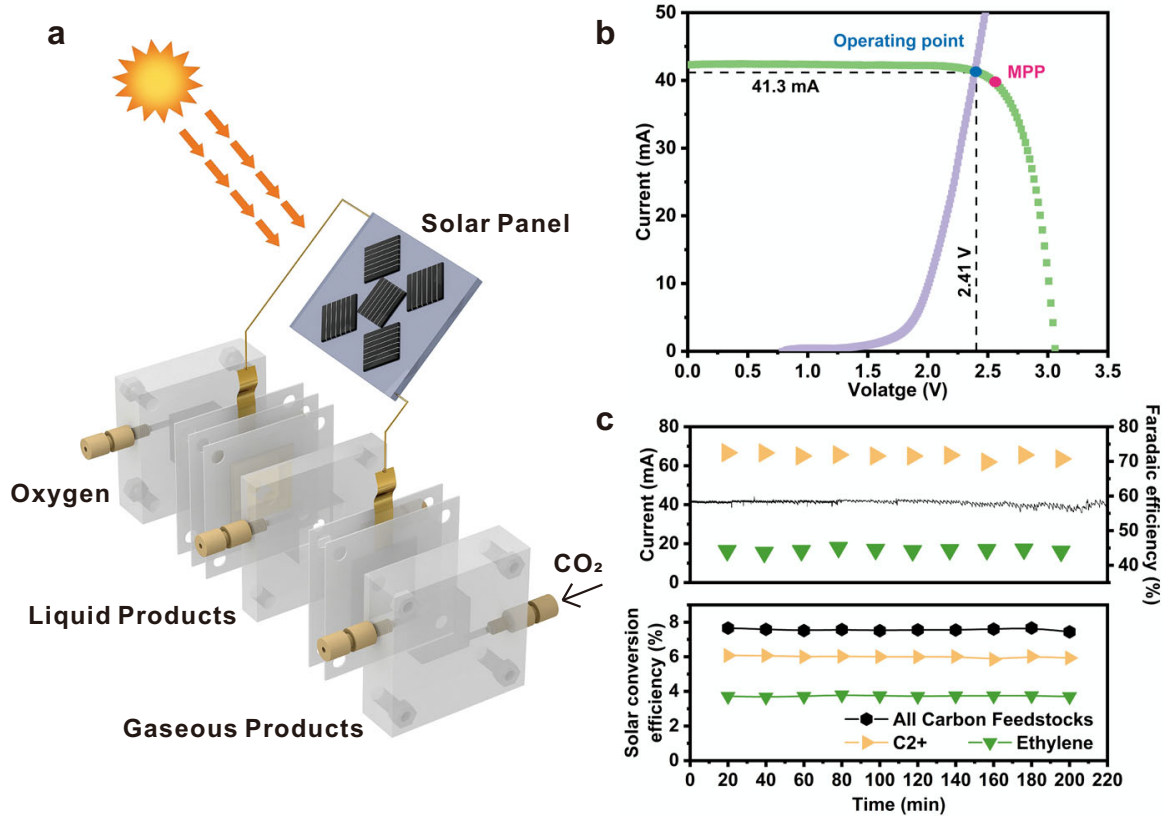

Fig. 4 Solar-powered $\mathbf{C O}_{2}$ reduction. a Schematic of the PV-EC system. $\mathbf{b}$ Photovoltaic and electrocatalytic I-V behaviors. The photovoltaic performance is shown under light (green) with the MPP marked by a red dot. The measured operating current of the $\mathrm{CO}_{2}$ electrolysis system (cathode, anode, and anion exchange membrane) at different voltages has been marked by the purple curve. The observed long-term operating point is marked by a blue dot, with the black dashed lines showing the corresponding current and voltage. c Faradaic efficiency towards ethylene and $\mathrm{C} 2+$ products, solar current, and solar conversion efficiency as a function of reaction time. Carbon feedstocks include CO, methane, ethylene, ethanol, and n-propanol. C2+ products include ethylene, ethanol, and n-propanol. 

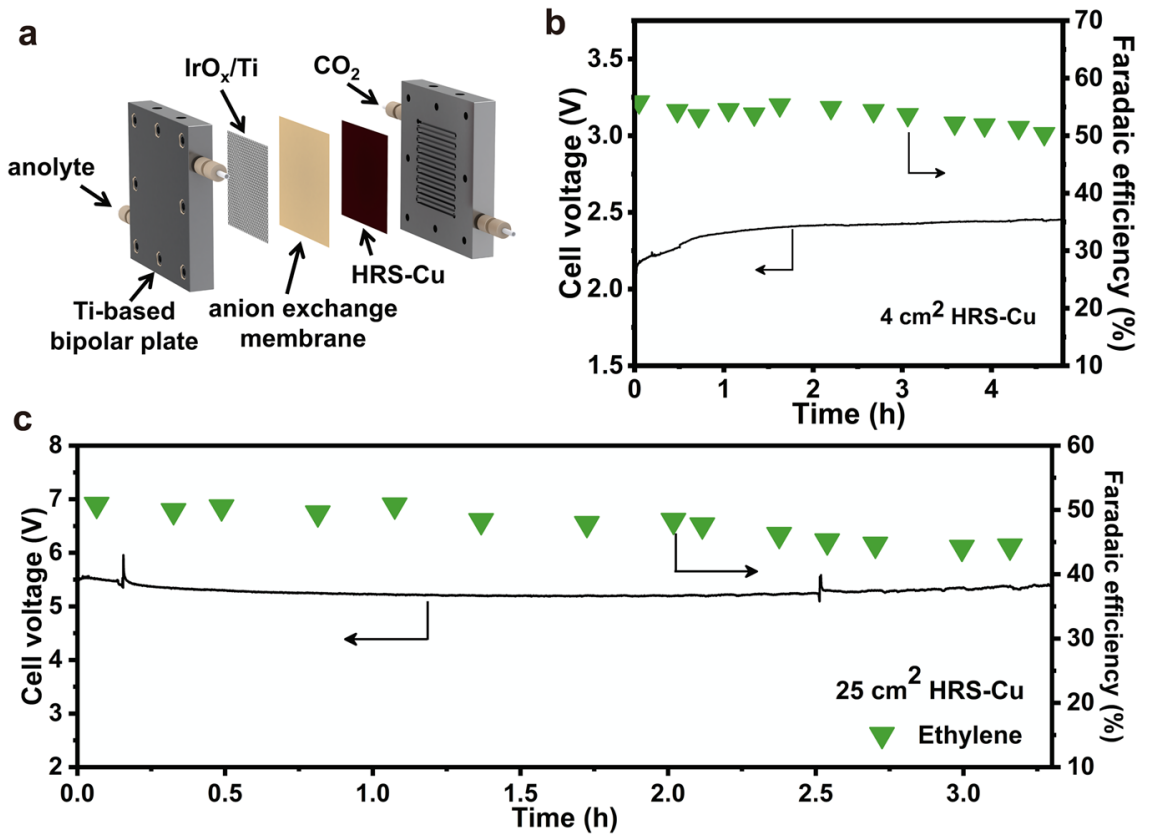

Fig. 5 Scaling up the $\mathbf{C O}_{\mathbf{2}}$ reduction system. a Schematic of the MEA system. The gaskets are not shown. $\mathbf{b}$ Stability test over a span of $\sim 4.5 \mathrm{~h}$ of $\mathrm{CO}_{2}{ }^{-}$ electrolysis in a $4 \mathrm{~cm}^{2}$-MEA system at the total current density of $120 \mathrm{~mA} \mathrm{~cm}^{-2}$. c Stability test over a span of $\sim 3.5 \mathrm{~h}$ of $\mathrm{CO}_{2}$-electrolysis in a $25 \mathrm{~cm}^{2}$-MEA system at the total current of $12 \mathrm{~A}$. The decrease in ethylene F.E. and the increase in cell voltage may be attributed to the formation of carbonate on the cathode side and the cathode water flooding.

$-0.55 \mathrm{~V}$ versus the RHE that yields $\sim 45$ and $\sim 72 \%$ F.E. for ethylene and $\mathrm{C} 2+$ products (containing ethylene), respectively (Fig. 2b). The deviation of these F.E.s from the maximized F.E.s for ethylene and $\mathrm{C} 2+$ products is because of the matching between electrolyzer and the solar panel towards the maximum power point (MPP) of the solar panel. Considering that the effective area of the HRS-Cu sample is $\sim 0.64 \mathrm{~cm}^{2}$, the operating current varies from 38.4 to $44.8 \mathrm{~mA}$. The widely available $\mathrm{p}-\mathrm{n}^{+}$ solar cells, with an open circuit potential of $\sim 0.6 \mathrm{~V}$ and a shortcircuit current density of $\sim 36 \mathrm{~mA} \mathrm{~cm}^{-2}$, were selected and cut into $\sim 1.14 \mathrm{~cm}^{2}$ pieces. By connecting five of them in series, the solar panel would provide the suitable voltage and current for the $\mathrm{CO}_{2}$ reduction electrolyzer near the MPP of the solar panel (i.e., the PV system). I-V curve of the obtained solar panel was measured under simulated AM 1.5G 1-sun illumination (Fig. 4b). This curve crosses the $\mathrm{I}-\mathrm{V}$ curve of the electrolyzer at the point (i.e., the operating point) where its cathodic current and voltage are $\sim 41.3 \mathrm{~mA}$ and $\sim 2.41 \mathrm{~V}$, respectively, which matches well with the MPP output metrics of the solar panel $(39.8 \mathrm{~mA}$ at $2.53 \mathrm{~V})$, indicating the optimum solar-to-electricity conversion process in our integrated device.

During $~ 3.7 \mathrm{~h}$ (220 min) of electrolysis powered by 1-sun solar illumination, the cathodic current of the electrolyzer was stable at $\sim 41.3 \mathrm{~mA}$ and the F.E. of ethylene and $\mathrm{C} 2+$ products stabilized at $\sim 45$ and $\sim 72 \%$, respectively (Fig. $4 \mathrm{c}$ and Supplementary Figs. 37-39). Although this selectivity is already deviated from the maximum F.E.s owing to MPP matching, such a PV-EC system still yields a solar-to-ethylene efficiency of $\sim 4.0 \%$ and a solar-to$\mathrm{C} 2+$ products efficiency of $\sim 6.0 \%$ (Fig. $4 \mathrm{c}$ ) under simulated 1 Sun illumination, which exceeds the efficiency of general natural photosynthesis for producing carbohydrates $(3-6 \%)^{54}$. Such efficiency is also able to match a recent state-of-the-art perovskite solar cells-powered $\mathrm{Cu}-\mathrm{Ag}$ bimetallic reaction system ${ }^{55}$, while a longer stability and larger $\mathrm{CO}_{2}$ reduction current are obtained in this system. The performance of this work also exceeds that of most previously reported copper-based PV-EC systems (Supplementary Table 4), which provides a benchmark for solar conversion efficiency while using feasibly available Si-based solar cells and earth-abundant low-cost electrode materials.

The membrane electrode assemble system (MEA) was further adopted to scale up the $\mathrm{CO}_{2}$ reduction system (Supplementary Fig. 40, details in "Methods"). On the cathode side, humidified $\mathrm{CO}_{2}$ gas was supplied (Fig. 5a), which reduces the direct contact between the catalyst and the aqueous electrolyte, while reducing the ohmic resistance of the electrolyte ${ }^{56,57}$. At the same time, the one-step deposition-etch-bombardment process proposed in this work is based on a widely used vacuum deposition process similar to the photovoltaic industries, thus its marginal cost for producing large-area electrodes can be largely reduced with mass production. In addition, this method does not require additional catalyst loading steps and does not use additional chemicals, accelerating the continuous preparation of large-area electrodes and avoiding potential electrode contamination. Therefore, the combination of a MEA reaction system and this preparation method is particularly suitable for the scale-up of $\mathrm{CO}_{2}$ reduction.

The electrode area was enlarged to $4 \mathrm{~cm}^{2}$, and the $\mathrm{CO}_{2}$ reduction performance test was performed in the MEA system (the area of cathodic flow fields is $4 \mathrm{~cm}^{2}$, referred as to the $4 \mathrm{~cm}^{2}$ MEA) at a current density of $120 \mathrm{~mA} \mathrm{~cm}^{-2}$ corresponding to the maximum ethylene F.E. (58.6\%) in the flow cell system (Fig. 5b). The optimal ethylene F.E. reaches $55.8 \%$, while the corresponding full-cell E.C.E of ethylene and C2+ products increase to 26.4 and $40.2 \%$, respectively. After $\sim 4.5 \mathrm{~h}$ of operation (Supplementary Fig. 41 ), the ethylene selectivity $(50.4 \%)$ still remains above $90 \%$ of the initial value $(55.8 \%)$. Although many works have obtained impressive $\mathrm{CO}_{2}$ reduction selectivity, the single-pass yield for $\mathrm{C} 2+$ products is generally low (mostly below $3 \%$, Supplementary Table 5). In order to improve the single-pass yield of $\mathrm{C} 2+$ products, it is vital to further increase the current density and electrode area without affecting the transport of $\mathrm{CO}_{2}$ (details in the "Methods"). Using the one-step method proposed in this work, a HRS-Cu electrode with $25 \mathrm{~cm}^{2}$ activity area could be easily fabricated with the deposition-etch-bombardment process (Supplementary Fig. 42). In a $25 \mathrm{~cm}^{2}$ MEA system (i.e., the area 
of cathodic flow fields is $25 \mathrm{~cm}^{2}$ ), the optimal ethylene F.E. of HRS-Cu reached $50.9 \%$ and maintained above $45 \%$ (Fig. $5 \mathrm{c}$ and Supplementary Fig. 43 ) after $\sim 3.5 \mathrm{~h}$ of operation at a total current of $12 \mathrm{~A}$ (i.e., $480 \mathrm{~mA} \mathrm{~cm}^{-2}$ ). The corresponding single-pass yield of $\mathrm{CO}_{2}$ towards $\mathrm{C} 2+$ products increased to and $13.2 \%$, with ethylene increased to $12.0 \%$. However, a corresponding decrease in E.C.E. was observed (Supplementary Table 5). Therefore, using more efficient anode materials, while controlling the operating conditions of the device such as temperature and pressure, or designing a new flow field structure to enhance $\mathrm{CO}_{2}$ mass transfer may be effective ways to further improve the E.C.E.

\section{Discussion}

In conclusion, this work demonstrates a deposition-etchbombardment process that feasibly increases the exposure of $\mathrm{Cu}(100)$ facets in low-cost nanostructured $\mathrm{Cu}$ films. This strategy obviates the use of capping agents, achieving precise control of surface structures in a one-step approach. The obtained $\mathrm{Cu}(100)$ rich film functions as a high-performance electrode for $\mathrm{CO}_{2}$ reduction towards ethylene and $\mathrm{C} 2+$ products. In flow cell, it realized ethylene and $\mathrm{C} 2+$ (containing ethylene) F.E.s of 58.6 and $86.6 \%$, respectively. In addition, this deposition-etchbombardment method bypasses the electrode assembly process, avoids the use of polymer binders, enhances the contact between the catalytic film and the substrate. Due to the above advantages, in flow cell, a corresponding full-cell E.C.E. of 24.8 and $36.5 \%$ for ethylene and $\mathrm{C} 2+$ products were obtained, respectively, which is a notable advance over existing single metallic $\mathrm{Cu}$-based systems. Moreover, this preparation method is flexible and easy to achieve electrode scale-up. When a $4 \mathrm{~cm}^{2}$ electrode was applied to the MEA system, the corresponding full-cell E.C.E. could be increased to 40.5 and $26.8 \%$, respectively, without compromising product selectivity. When the electrode area of the MEA system is increased to $25 \mathrm{~cm}^{2}$, the single-pass yield of $\mathrm{C} 2+$ products can be further increased to $13.2 \%$, with an ethylene yield of $12.0 \%$. In situ ATR-SEIRAS studies and theoretical calculations provide insights into the role of $\mathrm{Cu}(100)$ facets for increasing * CO coverage and reducing the energy barrier of $\mathrm{C}-\mathrm{C}$ coupling, vital for ethylene and $\mathrm{C} 2+$ products formation. The potential of using this $\mathrm{Cu}(100)$-rich film for photosynthesis was also demonstrated using renewable electricity generated by $\mathrm{Si}$ solar panels, achieving a solar-to-C2+ products efficiency of $\sim 6.0 \%$ under simulated 1 Sun illumination. Future research endeavors may focus on the generation of energetic particles (atoms, molecules, ions, etc.) in other environments such as solutions in ambient conditions, which may further reduce the cost of one-step facet control by this vacuum-based deposition-etch-bombardment method.

\begin{abstract}
Methods
Synthesis of LS-Cu, MS-Cu, HS-Cu. The deposition-etch-bombardment process was conducted in a custom-designed radio frequency (RF, $13.56 \mathrm{MHz}$ ) magnetron sputtering system (Supplementary Fig. 1a). For LS-Cu, Ar was delivered into the system. The deposition chamber was pumped down by a mechanical pump and a molecular pump that resulted in a base pressure of $2.0 \times 10^{-4} \mathrm{~Pa}$. The flow rate of Ar was set as 20 standard cubic centimeters per minute $(\mathrm{sccm})$. During the deposition, the RF power was $40 \mathrm{~W}$, and the working pressure was $4 \mathrm{~Pa}$. The deposition time was $15 \mathrm{~min}$. The target to substrate distance was set to $7 \mathrm{~cm}$. Commercial GDLs were cut into squares $(5 \times 5 \mathrm{~cm})$ for use as substrates. For MS$\mathrm{Cu}$, the RF power was set as $100 \mathrm{~W}$ and the deposition time was $7.5 \mathrm{~min}$, other conditions were the same as LS-Cu. For HS-Cu, the RF power was set as $200 \mathrm{~W}$ and the deposition time was $3.5 \mathrm{~min}$, other conditions were the same as LS-Cu.
\end{abstract}

Synthesis of LRS-Cu, MRS-Cu, and HRS-Cu. During the synthesis process of precatalysts of LRS-Cu, MRS-Cu, and HRS-Cu, $\mathrm{O}_{2}$ was also introduced to the Ar atmosphere. The flow rates of $\mathrm{Ar}$ and $\mathrm{O}_{2}$ were 20 and $4 \mathrm{sccm}$, respectively, to achieve a partial pressure of $\mathrm{O}_{2}$ of $0.67 \mathrm{~Pa}$. Other conditions were the same as those of LS-Cu, MS-Cu, and HS-Cu. The obtained precatalysts were pre-reduced at $-0.5 \mathrm{~V}$ versus the RHE for $1 \mathrm{~h}$ under the same conditions as $\mathrm{CO}_{2}$ electroreduction. Pre-reduction was carried out with a potentiostat (CompactStat.e20250, IVIUM).
After pre-reduction, the final samples (i.e., LRS-Cu, MRS-Cu, and HRS-Cu) were obtained.

Synthesis of $\mathbf{W}-\mathbf{C u}$. The $\mathrm{W}-\mathrm{Cu}$ was fabricated through the electrochemical prereduction of the $\mathrm{Cu}_{2} \mathrm{O}$ nanorods at $-0.5 \mathrm{~V}$ versus the $\mathrm{RHE}$ for 1 hour under the same conditions as $\mathrm{CO}_{2}$ electroreduction. After pre-reduction, the electrode was directly used for $\mathrm{CO}_{2}$ reduction. The $\mathrm{Cu}_{2} \mathrm{O}$ nanorods were prepared by annealing the $\mathrm{Cu}(\mathrm{OH})_{2}$ nanorods in the $\mathrm{Ar}$ atmosphere at $500^{\circ} \mathrm{C}$ for $2 \mathrm{~h}$ with a heating rate of $10^{\circ} \mathrm{C} \mathrm{min}-1$. The $\mathrm{Cu}(\mathrm{OH})_{2}$ nanorods were prepared by a previous method with some modifications ${ }^{32}$. The obtained $\mathrm{Cu}_{2} \mathrm{O}$ nanorods were airbrushed onto the commercial GDLs at an approximate loading of $0.9 \mathrm{mg} / \mathrm{cm}^{2}$ measured through weighing GDLs before and after airbrushing. The catalyst ink was prepared by dispersing $200 \mathrm{mg}$ of $\mathrm{Cu}_{2} \mathrm{O}$ nanorods and $50 \mu \mathrm{L}$ of Nafion Solution (Sigma-Aldrich) in $750 \mu \mathrm{L}$ isopropyl alcohol and $250 \mu \mathrm{L}$ of ultra-purity water $(18.2 \mathrm{M} \Omega \mathrm{cm})$ and sonicated for $1 \mathrm{~h}$ before airbrushing (H-SET, Paasche). Pre-reduction was carried out with a potentiostat (CompactStat.e20250, IVIUM).

Characterizations. Field-emission scanning electron microscopy (FESEM) (Hitachi $\mathrm{S}-4800,3 \mathrm{kV}$ ) was used to characterize the morphology and microstructure of the samples. Transmission electron microscopy (TEM), High-resolution TEM (HRTEM) images were obtained at $200 \mathrm{kV}$ (JEOL JEM-2100F). The crystal structure was determined by X-ray Diffractometer (XRD, Bruker D8 Focus) with $\mathrm{Cu}$ Ka radiation $(\lambda=1.54056 \AA)$ at $40 \mathrm{kV}$ and $40 \mathrm{~mA}$. XRD spectra were collected over a $2 \theta$ range of $30-60^{\circ}$ at a scanning speed of $8^{\circ} / \mathrm{min}$. XPS analyses of precatalysts were carried out on a Physical Electronics PHI 1600 ESCA system with an $\mathrm{Al} \mathrm{Ka} \mathrm{X-ray} \mathrm{source}(1486.6 \mathrm{eV})$. The binding energy was calibrated using the $\mathrm{C} 1 \mathrm{~s}$ photoelectron peak at $284.6 \mathrm{eV}$ as the reference.

In-situ Raman spectroscopy measurements. In-situ Raman spectroscopy was carried out in a custom-designed flow cell (Supplementary Fig. 12a), which was manufactured by Gaossunion Co., Ltd., Tianjin. The electrode was encased in a PEEK fitting, with an exposed circular geometric surface area of $\sim 1 \mathrm{~cm}^{2}$. A platinum wire and an $\mathrm{Ag} / \mathrm{AgCl}$ electrode (saturated $\mathrm{KCl}, \mathrm{Gaossunion} \mathrm{Co} ., \mathrm{Ltd} .$, Tianjin) were used as the counter and the reference electrode, respectively. The counter electrode is separated from the working electrode by an anion exchange membrane (FAA-3-PK-75, Fumatech) to avoid cross-contamination. In situ Raman spectroscopy was performed with a Raman microscopy system (LabRAM HR Evolution, Horiba Jobin Yvon). A He-Ne laser $(\lambda=532 \mathrm{~nm})$ served as the excitation source. All spectra were collected at a constant potential $(-0.5 \mathrm{~V}$ versus the RHE). Electrochemical measurements were carried out with a potentiostat (CompactStat.e20250, IVIUM).

In-situ ATR-SEIRAS measurements. In-situ ATR-SEIRAS was performed with an ATR configuration. Au nanofilms were deposited directly on the reflecting plane of a Si prism using a modified electroless chemical deposition method outlined by $\mathrm{Xu}$ et al. ${ }^{58}$. The spectroelectrochemical cell was based on the design of $\mathrm{Xu}$ et al. ${ }^{59}$ and manufactured by Gaossunion Co., Ltd., Tianjin. In order to reduce the corrosion of Si crystal, $0.1 \mathrm{M} \mathrm{KOH}$ was used as the electrolyte. The counter electrode (a graphite rod) was separated from the working and reference electrodes, i.e., the catalyst film and a saturated $\mathrm{Ag} / \mathrm{AgCl}$ electrode (saturated $\mathrm{KCl}$, Gaossunion Co., Ltd., Tianjin), respectively, with a piece of anion exchange membrane (AEM, FAA 3-PK-75, Fumatech). This cell is integrated into the FTIR (is50, Nicolet) spectrometer with a modified accessory at a $60^{\circ}$ incident angle (VeeMax III, PIKE Technology). All spectra were collected with a $4 \mathrm{~cm}^{-1}$ resolution. Spectra are presented in absorbance, with positive and negative peaks showing an increase and decrease in signal, respectively. As for LRS-Cu, MRS-Cu and $\mathrm{HRS}-\mathrm{Cu}$, they were deposited on the Au nanofilm coated-Si prisms like the process described above, while $\mathrm{W}-\mathrm{Cu}$ was drop-casted onto the Au nanofilm coated-Si prisms. The background was taken at $+0.1 \mathrm{~V}$ versus the RHE in Ar saturated electrolyte for each electrode. Electrochemical measurements are carried out with a potentiostat (CompactStat.e20250, IVIUM).

$\mathbf{O H}^{-}$electroadsorption measurements. In-situ $\mathrm{OH}_{\text {ads }}$ studies were conducted by flowing $\mathrm{Ar}$ in the flow cell (Supplementary Fig. 15). First, $\mathrm{CO}_{2}$ electrolysis was conducted at a constant potential of $-0.5 \mathrm{~V}$ versus the RHE for $1 \mathrm{~h}$ by switching the gas feed to $\mathrm{CO}_{2}$ and flowing the electrolyte. Immediately after electrolysis, the electrolyte (1 $\mathrm{M} \mathrm{NaOH}$ (a.q.)) flow rate was stopped to minimize the fluctuation in the voltammogram, and the gas feed was switched to Ar, the electrolyte flow rate was stopped, and then cyclic voltammetry $(20 \mathrm{mV} / \mathrm{s})$ was performed. Electrochemical measurements are carried out with a potentiostat (Autolab PGSTAT204, Metrohm).

ECSA measurements. The ECSA was determined by measuring the double-layer capacitance $\left(\mathrm{C}_{\mathrm{DL}}\right)$ of various electrodes in Ar-purged $2 \mathrm{M} \mathrm{KOH} \mathrm{(aq.)} \mathrm{in} \mathrm{the} \mathrm{flow}$ cell (Supplementary Fig. 15) and the ECSA was measured after $\mathrm{CO}_{2}$ electrolysis at a constant potential of $-0.5 \mathrm{~V}$ versus the RHE for $1 \mathrm{~h}$. Immediately after electrolysis, the gas feed was switched to $\mathrm{Ar}$, and then the electrolyte flow rate was stopped to 
minimize the fluctuation in the voltammogram. The scan rate was varied from 25 to $125 \mathrm{mV} \mathrm{s}^{-1}$ in the non-faradaic potential region and the observed current was plotted as a function of scan rate to obtain the $\mathrm{C}_{\mathrm{DL}}$. ECSA was determined by normalizing the $\mathrm{C}_{\mathrm{DL}}$ to that of a $\mathrm{Cu}$ foil. Electrochemical measurements are carried out with a potentiostat (CHI 660E, CH Instruments Inc.).

Electrochemical reduction of $\mathrm{CO}_{\mathbf{2}}$ in a flow cell. $\mathrm{CO}_{2}$ reduction was conducted in a custom-designed three-chamber flow cell manufactured by Gaossunion Co., Ltd. (Supplementary Fig. 15), where the $\mathrm{CO}_{2}$ gas was supplied directly to the catalyst layer (cathode, working electrode). The $\mathrm{CO}_{2}$ gas flow rate was controlled using a mass flow controller (MC-Series, Alicat Scientific) and set to $10 \mathrm{sccm}$. However, it is well known that $\mathrm{OH}^{-}$can react with $\mathrm{CO}_{2}$ to form $\mathrm{HCO}_{3}{ }^{-}$or $\mathrm{CO}_{3}{ }^{2-}$. Therefore, the calculation based on the inlet $\mathrm{CO}_{2}$ flow rate will result in overestimated F.E. results ${ }^{60,61}$. For this reason, we used another flowmeter (M-Series, Alicat Scientific) to detect the $\mathrm{CO}_{2}$ flow rate at the outlet of the reactor and used this number as the basis for calculating F.E. Aqueous KOH solution $(2 \mathrm{M})$ was used as both the catholyte and the anolyte. Activated $\mathrm{Ni}$ foam was used as the anode (counter electrode). Peristaltic pumps (EC200-01, Gaossunion Co., Ltd.) were used to control the flow rate of the electrolytes at $\sim 10 \mathrm{ml} \mathrm{min}^{-1}$. An AEM (FAA-3-PK-75, Fumatech) was used to separate the cathode and anode chambers. Electrolysis experiments were conducted using chronoamperometry with a potentiostat (CompactStat.e20250, IVIUM). The cathode potentials were measured against a $\mathrm{Hg} / \mathrm{HgO}$ reference electrode (1 M KOH, Gaossunion Co., Ltd., Tianjin). For each measurement, products were quantified after the amount of electron flowing through the cathode achieved $50 \mathrm{C}$ and at least three replicates were conducted to obtain an average value with the standard deviation. It should be noted that $i R$ correction was not performed.

Electrochemical reduction of $\mathrm{CO}_{\mathbf{2}}$ in the MEA system. The MEA cell (manufactured by Gaossunion Co., Ltd.) consists of a titanium anode (cathode) bipolar plate with serpentine flow field, associated nuts, bolts, and insulating kit. The geometric area of each flow field is 4 or $25 \mathrm{~cm}^{2}$ (Supplementary Fig. 40). An AEM membrane (FAA-3-PK-75, Fumatech) was activated in $0.1 \mathrm{M} \mathrm{KOH}$ for $24 \mathrm{~h}$, washed with ultra-purity water prior to use. The anode consisted of iridium oxide supported on titanium mesh (IrOx/Ti mesh) was prepared by a dip-coating and thermal decomposition method ${ }^{62}$. The MEA was assembled in a way as illustrated in Fig. 5a. A direct current power supply (UTP1300, UNI-T Group Co., Ltd) was used to apply current to the MEA. A Corrtest CS350M in a galvanostatic mode was used to measure the cell voltage. No iR compensation was applied. Aqueous $\mathrm{KHCO}_{3}$ electrolyte $(0.1 \mathrm{M})$ was used as the anolyte and was circulated using a peristaltic pump (EC200-01, Gaossunion Co., Ltd.). The electrolyte flow rate was kept at $10 \mathrm{~mL} \mathrm{~min}{ }^{-1}$. As the current density and electrode area increase, the $\mathrm{CO}_{2}$ flow rate should be adjusted upwards to avoid mass transfer limitations of $\mathrm{CO}_{2}$ while maintaining optimum selectivity. The flow rate of the $\mathrm{CO}_{2}$ gas flowing into the cathode flow field was kept at 20 or $60 \mathrm{sccm}$ by a mass flow controller (MCSeries, Alicat Scientific) for different geometries of the flow field. $\mathrm{CO}_{2}$ was flowed through a homemade humidifier (7/8 full of Milli-Q water, room temperature) prior to the MEA. The flow rate of the $\mathrm{CO}_{2}$ gas flowing out the cathode flow field was also measured by a flowmeter (M-Series, Alicat Scientific). The liquid products carried by $\mathrm{CO}_{2}$ gas are absorbed by low-temperature ultra-purity water obtained from an ice salt bath

Analysis of $\mathrm{CO}_{2}$ reduction products. During electrolysis, gas products were quantified using an on-line gas chromatography system (GC7890B, Agilent Technologies, Inc.). The thermal conductivity detector (TCD) connected to a MolSieve 5A packed column (Agilent Technologies, Inc.) to detect $\mathrm{H}_{2}, \mathrm{O}_{2}$, and $\mathrm{N}_{2}$ and a back flame ionization detector (FID) connected to a Porapak Q packed column (Agilent Technologies, Inc.) to detect CO. A methanizer was installed to enable the back FID to detect $\mathrm{CO}$ with 1000 times higher sensitivity. A front FID connected to an HP-PLOT $\mathrm{Al}_{2} \mathrm{O}_{3}$ capillary column (Agilent Technologies, Inc.) to detect hydrocarbons (C1 C3). Ar was used as the carrier gas. After passing through the reactor, the gas was allowed to flow directly into the gas sampling loop of the gas chromatography for online gaseous product analysis.

In the performance test using flow cell and the MEA system, the liquid products were collected from the cathode and anode chambers ${ }^{60}$. The liquid products were analyzed by headspace gas chromatography (HS-GC) and ${ }^{1} \mathrm{H}-\mathrm{NMR}$. HS-GC measurements were carried out using a BCHP HS-2 Headspace Sampler with GC2060 gas chromatography (Shanghai Ruimin Instrument Co., Ltd.). Typically, $10 \mathrm{~mL}$ vials were filled with $3 \mathrm{~mL}$ of the liquid sample and sealed. They were heated to $70{ }^{\circ} \mathrm{C}$ over $20 \mathrm{~min}$ in the headspace sampler and $1 \mathrm{~mL}$ of the headspace gas composition was automatically injected into the GC. The sample loop $\left(110^{\circ} \mathrm{C}\right)$ and transfer line $\left(110^{\circ} \mathrm{C}\right)$ were both heated to avoid condensation. Ar was used as the carrier gas. An HP-INNOWax capillary column (Length: $60 \mathrm{~m}$; ID: $0.32 \mathrm{~mm}$; Film: $0.5 \mu \mathrm{m}$, Agilent) was used to separate the compounds in the sample. ${ }^{1} \mathrm{H}-\mathrm{NMR}$ was performed using AVANCE IIITM HD $400 \mathrm{MHz}$ NanoBAY. The water suppression method was used. DMSO $(10 \mathrm{mM})$ and phenol $(50 \mathrm{mM})$ were added as internal standards. For $\mathrm{CO}_{2}$ reduction products showing multiple sets of NMR peaks, the set of peaks with the highest intensity were chosen for calibration and quantification.

Construction of the photovoltaic-electrolyzer (PV-EC) system. The simulated solar illumination was obtained from a $300 \mathrm{~W}$ Xenon arc lamp (Microsolar 300 UV, Beijing Perfectlight Technology Co. Ltd.) equipped with an air mass 1.5 global (AM 1.5G) filter, and the power intensity of the incident light was calibrated to $100 \mathrm{~mW} / \mathrm{cm}^{2}$ using a Si photodiode (FDS100, Thorlabs). The solar panel was based on five $\mathrm{p}-\mathrm{n}^{+} \mathrm{Si}$ solar cells connected in series (effective illuminated area of $\sim 5.7 \mathrm{~cm}^{2}$ ). A Source Measure Unit (2450, Keithely) was wired in series with $0 \mathrm{~V}$ applied to monitor the current. The electrolyzer is the flow cell.

Computational methods. Vienna ab initio simulation package (VASP) was used to carry out calculations with the PBE exchange-correlation functional ${ }^{63,64}$. Van der Waals interactions were accounted for by using the DFT-D3 method ${ }^{65}$. The cut-off energy is $400 \mathrm{eV}$. The interactions between the atomic cores and electrons were described by the projector augmented wave (PAW) method $^{66}$. All structures were optimized until the force on each atom has been less than $0.02 \mathrm{eV} / \AA$. The transition state search was conducted with the climbing image nudged elastic band (CI-NEB) method, followed by the dimer method to converge the saddle point within $0.05 \mathrm{eV} / \AA$. We access $\mathrm{CO}$ dimerization on the three models. A four-layer $\mathrm{Cu}(111)$ $(3 \times 3)$ slab with a $(3 \times 3 \times 1) \mathrm{k}$-point grid and a four-layer $\mathrm{Cu}(100)-(3 \times 3)$ slab with a $(3 \times 3 \times 1)$ k-point grid were used as models for DFT calculations. The bottom two layers are fixed while the upper two layers were relaxed during optimization. One layer of water with a simple hydronium ion was chosen to simulate the electrochemical interface ${ }^{67-69}$

\section{Data availability}

The authors declare that all data supporting the results of this study are available within the paper and its supplementary information files or from the corresponding authors upon reasonable request.

Received: 3 June 2021; Accepted: 6 September 2021; Published online: 30 September 2021

\section{References}

1. Kattel, S., Ramirez, P. J., Chen, J. G., Rodriguez, J. A. \& Liu, P. Active sites for $\mathrm{CO} 2$ hydrogenation to methanol on $\mathrm{Cu} / \mathrm{ZnO}$ catalysts. Science 355, 1296-1299 (2017).

2. Dinh, C. T. et al. CO2 electroreduction to ethylene via hydroxidemediated copper catalysis at an abrupt interface. Science 360, 783-787 (2018).

3. Nitopi, S. et al. Progress and perspectives of electrochemical CO2 reduction on copper in aqueous electrolyte. Chem. Rev. 119, 7610-7672 (2019).

4. Li, F. et al. Molecular tuning of CO2-to-ethylene conversion. Nature 577, 509-513 (2020)

5. Yang, P. P. et al. Protecting copper oxidation state via intermediate confinement for selective $\mathrm{CO} 2$ electroreduction to $\mathrm{C} 2+$ fuels. J. Am. Chem. Soc. 142, 6400-6408 (2020).

6. Zhong, $\mathrm{M}$. et al. Accelerated discovery of $\mathrm{CO} 2$ electrocatalysts using active machine learning. Nature 581, 178-183 (2020).

7. Ma, W. C. et al. Electrocatalytic reduction of $\mathrm{CO} 2$ to ethylene and ethanol through hydrogen-assisted $\mathrm{C}-\mathrm{C}$ coupling over fluorine-modified copper. Nat. Catal. 3, 478-487 (2020).

8. Jung, $\mathrm{H}$. et al. Electrochemical fragmentation of $\mathrm{Cu} 2 \mathrm{O}$ nanoparticles enhancing selective $\mathrm{C}-\mathrm{C}$ coupling from $\mathrm{CO} 2$ reduction reaction. J. Am. Chem Soc. 141, 4624-4633 (2019).

9. Durand, W. J., Peterson, A. A., Studt, F., Abild-Pedersen, F. \& Norskov, J. K. Structure effects on the energetics of the electrochemical reduction of $\mathrm{CO} 2$ by copper surfaces. Surf. Sci. 605, 1354-1359 (2011).

10. Jiang, $\mathrm{K}$. et al. Metal ion cycling of $\mathrm{Cu}$ foil for selective $\mathrm{C}-\mathrm{C}$ coupling in electrochemical CO2 reduction. Nat. Catal. 1, 111-119 (2018).

11. Xia, Y., Xiong, Y., Lim, B. \& Skrabalak, S. E. Shape-controlled synthesis of metal nanocrystals: simple chemistry meets complex physics? Angew. Chem. Int. Ed. 48, 60-103 (2009)

12. Wang, Z., Yang, G., Zhang, Z., Jin, M. \& Yin, Y. Selectivity on etching: creation of high-energy facets on copper nanocrystals for CO2 electrochemical reduction. ACS Nano 10, 4559-4564 (2016).

13. De Gregorio, G. L. et al. Facet-dependent selectivity of $\mathrm{Cu}$ catalysts in electrochemical $\mathrm{CO} 2$ reduction at commercially viable current densities. ACS Catal. 10, 4854-4862 (2020).

14. Wang, H. X. et al. Self-selective catalyst synthesis for $\mathrm{CO} 2$ reduction. Joule 3, 1927-1936 (2019) 
15. Wang, Y. et al. Catalyst synthesis under $\mathrm{CO} 2$ electroreduction favours faceting and promotes renewable fuels electrosynthesis. Nat. Catal. 3, 98-106 (2019).

16. Tao, A. R., Habas, S. \& Yang, P. D. Shape control of colloidal metal nanocrystals. Small 4, 310-325 (2008).

17. Niu, Z. \& Li, Y. Removal and utilization of capping agents in nanocatalysis. Chem. Mater. 26, 72-83 (2013).

18. Hou, Y. H. et al. Photonic curing: activation and stabilization of metal membrane catalysts (MMCs) for the electrochemical reduction of $\mathrm{CO} 2$. ACS Catal. 9, 9518-9529 (2019).

19. Nwabara, U. O., Cofell, E. R., Verma, S., Negro, E. \& Kenis, P. J. A. Durable cathodes and electrolyzers for the efficient aqueous electrochemical reduction of CO2. ChemSusChem 13, 855-875 (2020).

20. Yang H., et al. Recent progress in self-supported catalysts for $\mathrm{CO} 2$ electrochemical reduction. Small Methods 4, 1900826 (2020).

21. Ott, S. et al. Ionomer distribution control in porous carbon-supported catalyst layers for high-power and low Pt-loaded proton exchange membrane fuel cells. Nat. Mater. 19, 77-85 (2020).

22. Zhou, Y.-G., Kang, Y. \& Huang, J. Fluidized electrocatalysis. CCS Chem. 2, 31-41 (2020)

23. Wei, X., Li, Y., Chen, L. \& Shi, J. Formic acid electro-synthesis by concurrent cathodic $\mathrm{CO} 2$ reduction and anodic $\mathrm{CH} 3 \mathrm{OH}$ oxidation. Angew. Chem. Int. Ed. 60, 3148-3155 (2021).

24. Dobrev, D. Ion-beam-induced texture formation in vacuum-condensed thin metal films. Thin Solid Films 92, 41-53 (1982).

25. Abadias, G. Stress and preferred orientation in nNitride-based PVD coatings. Surf. Coat. Technol. 202, 2223-2235 (2008).

26. Lv, Y. H. et al. Influence of substrate bias voltage on structure and properties of the CrAlN films deposited by unbalanced magnetron sputtering. Appl. Surf. Sci. 258, 3864-3870 (2012)

27. Zheng, J. Y., Bao, S. H., Guo, Y. \& Jin, P. Anatase TiO2 films with dominant $\{001\}$ facets fabricated by direct-current reactive magnetron sputtering at room temperature: oxygen defects and enhanced visible-light photocatalytic behaviors. ACS Appl. Mater. Interfaces 6, 5940-5946 (2014).

28. $\mathrm{Li}, \mathrm{F}$. et al. Cooperative $\mathrm{CO} 2$-to-ethanol conversion via enriched intermediates at molecule-metal catalyst interfaces. Nat. Catal. 3, 75-82 (2019).

29. Cao, L. et al. Mechanistic insights for low-overpotential electroreduction of CO2 to CO on copper nanowires. ACS Catal. 7, 8578-8587 (2017)

30. Droog, J. M. M. \& Schlenter, B. Oxygen electrosorption on copper single crystal electrodes in sodium hydroxide solution. J. Electroanal. Chem. Interfacial Electrochem. 112, 387-390 (1980).

31. Schouten, K. J., Qin, Z., Perez Gallent, E. \& Koper, M. T. Two pathways for the formation of ethylene in $\mathrm{CO}$ reduction on single-crystal copper electrodes. J. Am. Chem. Soc. 134, 9864-9867 (2012).

32. Lv, J. J. et al. A highly porous copper electrocatalyst for carbon dioxide reduction. Adv. Mater. 30, e1803111 (2018).

33. LaGrow, A. P., Ward, M. R., Lloyd, D. C., Gai, P. L. \& Boyes, E. D. Visualizing the $\mathrm{Cu} / \mathrm{Cu} 2 \mathrm{O}$ interface transition in nanoparticles with environmental scanning transmission electron microscopy. J. Am. Chem. Soc. 139, 179-185 (2017).

34. Feng, X., Jiang, K., Fan, S. \& Kanan, M. W. Grain-boundary-dependent CO2 electroreduction activity. J. Am. Chem. Soc. 137, 4606-4609 (2015).

35. Jin, M. et al. Shape-controlled synthesis of copper nanocrystals in an aqueous solution with glucose as a reducing agent and hexadecylamine as a capping agent. Angew. Chem. Int. Ed. 50, 10560-10564 (2011).

36. Wang, X., Varela, A. S., Bergmann, A., Kuhl, S. \& Strasser, P. Catalyst particle density controls hydrocarbon product selectivity in $\mathrm{CO} 2$ electroreduction on CuOx. ChemSusChem 10, 4642-4649 (2017).

37. Kas, R. K. et al. Electrochemical $\mathrm{CO} 2$ reduction on nanostructured metal electrodes: fact or defect? Chem. Sci. 11, 1738-1749 (2020).

38. Reske, R. et al. Controlling catalytic selectivities during $\mathrm{CO} 2$ electroreduction on thin $\mathrm{Cu}$ metal overlayers. J. Phy. Chem. Lett. 4, 2410-2413 (2013).

39. Tan, Y. C., Lee, K. B., Song, H. \& Oh, J. Modulating local CO2 concentration as a general strategy for enhancing $\mathrm{C}-\mathrm{C}$ coupling in $\mathrm{CO} 2$ electroreduction. Joule 4, 1104-1120 (2020).

40. Lee, $\mathrm{S}$. $\mathrm{H}$. et al. Oxidation state and surface reconstruction of $\mathrm{Cu}$ under $\mathrm{CO} 2$ reduction conditions from in situ $\mathrm{x}$-ray characterization. J. Am. Chem. Soc. 143, 588-592 (2021).

41. Jouny, M., Luc, W. \& Jiao, F. High-rate electroreduction of carbon monoxide to multi-carbon products. Nat. Catal. 1, 748-755 (2018).

42. Heyes, J., Dunwell, M. \& Xu, B. $\mathrm{CO} 2$ reduction on $\mathrm{Cu}$ at low overpotentials with surface-enhanced in situ spectroscopy. J. Phy. Chem. C. 120, 17334-17341 (2016).

43. Sartin, M. M. et al. Effect of particle shape and electrolyte cation on CO adsorption to copper oxide nanoparticle electrocatalysts. J. Phys. Chem. C. 122, 26489-26498 (2018)

44. Gunathunge, C. M., Ovalle, V. J., Li, Y. W., Janik, M. J. \& Waegele, M. M. Existence of an electrochemically inert $\mathrm{CO}$ population on $\mathrm{Cu}$ electrodes in alkaline pH. ACS Catal. 8, 7507-7516 (2018).
45. Ren, D., Fong, J. \& Yeo, B. S. The effects of currents and potentials on the selectivities of copper toward carbon dioxide electroreduction. Nat. Commun. 9, 925 (2018)

46. Ren, D., Gao, J., Zakeeruddin, S. M. \& Grätzel, M. New insights into the interface of electrochemical flow cells for carbon dioxide reduction to ethylene. J. Phys. Chem. Lett. 12, 7583-7589 (2021).

47. Goodpaster, J. D., Bell, A. T. \& Head-Gordon, M. Identification of possible pathways for $\mathrm{C}-\mathrm{C}$ bond formation during electrochemical reduction of $\mathrm{CO} 2$ new theoretical insights from an improved electrochemical model. J. Phys. Chem. Lett. 7, 1471-1477 (2016).

48. Schreier, M., Yoon, Y., Jackson, M. N. \& Surendranath, Y. Competition between $\mathrm{H}$ and $\mathrm{CO}$ for active sites governs copper-mediated electrosynthesis of hydrocarbon fuels. Angew. Chem. Int. Ed. 57, 10221-10225 (2018).

49. Clark, E. L., Hahn, C., Jaramillo, T. F. \& Bell, A. T. Electrochemical CO2 reduction over compressively strained $\mathrm{CuAg}$ surface alloys with enhanced multi-carbon oxygenate selectivity. J. Am. Chem. Soc. 139, 15848-15857 (2017).

50. $\mathrm{Li}$, J. et al. Constraining CO coverage on copper promotes high-efficiency ethylene electroproduction. Nat. Catal. 2, 1124-1131 (2019).

51. Malkani, A. S., Dunwell, M. \& Xu, B. Operando spectroscopic investigations of copper and oxide-derived copper catalysts for electrochemical $\mathrm{CO}$ reduction. ACS Catal. 9, 474-478 (2018).

52. Sandberg, R. B., Montoya, J. H., Chan, K. \& Norskov, J. K. CO-CO coupling on $\mathrm{Cu}$ facets: coverage, strain, and field effects. Surf. Sci. 654, 56-62 (2016).

53. Resasco, J. et al. Promoter effects of alkali metal cations on the electrochemical reduction of carbon dioxide. J. Am. Chem. Soc. 139, 11277-11287 (2017).

54. Ren, D., Loo, N. W. X., Gong, L. \& Yeo, B. S. Continuous production of ethylene from carbon dioxide and water using intermittent sunlight.ACS Sustain. Chem. Eng. 5, 9191-9199 (2017).

55. Gao, J. et al. Selective $\mathrm{C}-\mathrm{C}$ coupling in carbon dioxide electroreduction via efficient spillover of intermediates as supported by operando Raman pectroscopy. J. Am. Chem. Soc. 141, 18704-18714 (2019).

56. Weng, L. C., Bell, A. T. \& Weber, A. Z. Modeling gas-diffusion electrodes for CO2 reduction. Phys. Chem. Chem. Phys. 20, 16973-16984 (2018).

57. Burdyny, T. \& Smith, W. A. CO2 reduction on gas-diffusion electrodes and why catalytic performance must be assessed at commercially-relevant conditions. Energy Environ. Sci. 12, 1442-1453 (2019).

58. Dunwell, M. et al. The central role of bicarbonate in the electrochemical reduction of carbon dioxide on gold. J. Am. Chem. Soc. 139, 3774-3783 (2017).

59. Li, J. et al. Electrokinetic and in situ spectroscopic investigations of $\mathrm{CO}$ electrochemical reduction on copper. Nat. Commun. 12, 3264 (2021).

60. Zhang, J., Luo, W. \& Zuttel, A. Crossover of liquid products from electrochemical $\mathrm{CO} 2$ reduction through gas diffusion electrode and anion exchange membrane. J. Catal. 385, 140-145 (2020).

61. $\mathrm{Ma}, \mathrm{M}$. et al. Insights into the carbon balance for $\mathrm{CO} 2$ electroreduction on $\mathrm{Cu}$ using gas diffusion electrode reactor designs. Energy Environ. Sci. 13, 977-985 (2020).

62. Luc, W., Rosen, J. \& Jiao, F. An Ir-based anode for a practical CO2 electrolyzer. Catal. Today 288, 79-84 (2017).

63. Kresse, G. \& Hafner, J. Ab initio molecular-dynamics simulation of the liquidmetal-amorphous-semiconductor transition in germanium. Phys. Rev. B Condens. Matter 49, 14251-14269 (1994)

64. Grimme, S., Antony, J., Ehrlich, S. \& Krieg, H. A consistent and accurate ab initio parametrization of density functional dispersion correction (DFT-D) for the 94 elements H-Pu. J. Chem. Phys. 132, 154104 (2010).

65. Liu, S., Zong, J., Zhao, Z.-J. \& Gong, J. Exploring the initial oxidation of Pt, Pt3Ni, Pt3Au (111) surfaces: a genetic algorithm based global optimization with density functional theory. Green. Chem. Eng. 1, 56-62 (2020).

66. Kresse, G. \& Joubert, D. From ultrasoft pseudopotentials to the projector augmented-wave method. Phys. Rev. B 59, 1758-1775 (1999).

67. Gauthier, J. A., Dickens, C. F., Chen, L. D., Doyle, A. D. \& Norskov, J. K. Solvation effects for oxygen evolution reaction catalysis on $\mathrm{IrO} 2(110)$. J. Phys. Chem. C. 121, 11455-11463 (2017).

68. Montoya, J. H., Shi, C., Chan, K. \& Norskov, J. K. Theoretical insights into a $\mathrm{CO}$ dimerization mechanism in $\mathrm{CO} 2$ electroreduction. J. Phys. Chem. Lett. 6 , 2032-2037 (2015)

69. Cheng, D. et al. The nature of active sites for carbon dioxide electroreduction over oxide-derived copper catalysts. Nat. Commun. 12, 395 (2021).

\section{Acknowledgements}

We acknowledge the National Key R\&D Program of China (2016YFB0600901), the National Natural Science Foundation of China (22038009, 21722608, 51861125104, 2212100031), the Natural Science Foundation of Tianjin City (18JCJQJC47500), and the Program of Introducing Talents of Discipline to Universities (B06006) for financial support. 


\section{Author contributions}

J.L.G. supervised the project. J.L.G., T.W., G.Z., and Z.J.Z. conceptualized the project. G.Z. H.M.L., and H.G synthesized Cu-based catalysts. G.Z., H.Y.W., J. Y., and J.Y.G. conducted the catalytic tests and the related data processing. Q.Z.W. fabricated the solar panel. Z.J.Z. and D.F.C. carried out the theoretical calculations. All the authors participate in the writing of the paper.

\section{Competing interests}

The authors declare no competing interests.

\section{Additional information}

Supplementary information The online version contains supplementary material available at https://doi.org/10.1038/s41467-021-26053-w.

Correspondence and requests for materials should be addressed to Tuo Wang or Jinlong Gong.

Peer review information Nature Communications thanks Wei An, Antonio José Martín, and the other, anonymous, reviewer(s) for their contribution to the peer review of this work.
Reprints and permission information is available at http://www.nature.com/reprint

Publisher's note Springer Nature remains neutral with regard to jurisdictional claims in published maps and institutional affiliations.

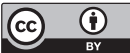

Open Access This article is licensed under a Creative Commons Attribution 4.0 International License, which permits use, sharing, adaptation, distribution and reproduction in any medium or format, as long as you give appropriate credit to the original author(s) and the source, provide a link to the Creative Commons license, and indicate if changes were made. The images or other third party material in this article are included in the article's Creative Commons license, unless indicated otherwise in a credit line to the material. If material is not included in the article's Creative Commons license and your intended use is not permitted by statutory regulation or exceeds the permitted use, you will need to obtain permission directly from the copyright holder. To view a copy of this license, visit http://creativecommons.org/ licenses/by/4.0/.

(C) The Author(s) 2021 